\title{
EMPRESA, NEGOCIOS Y PODER LOCAL EN EL MONTEVIDEO DE LA MODERNIZACIÓN Y DEL MILITARISMO (1865-1886)
}

\author{
Enterprise, business and local power \\ in the Montevideo of modernisation \\ and militarism (1865-1886)
}

\author{
Manuel Talamante Pérez \\ Universidad de Huelva, España
}

\begin{abstract}
Resumen: El poder local es uno de los escenarios en los que mejor se pueden observar los vínculos entre el tejido empresarial, los negocios y la política. En 1877, un año después de la llegada al poder como gobernador provisorio de Lorenzo Latorre, tiene lugar una reunión que afianzará aún más su poder autoritario en Uruguay. En ella intervienen miembros de lo más selecto del país, con participación directa en el poder local montevideano: la Junta Económica Administrativa. A partir de la consulta de fuentes notariales y protocolos comerciales, así como de otras procedentes de la propia institución analizada, se identificarán quiénes fueron dichos individuos y cuáles fueron sus relaciones con la política municipal, la empresa y los negocios en el militarismo uruguayo.
\end{abstract}

Palabras clave: empresa, negocios, poder local, Montevideo, Uruguay.

\begin{abstract}
Local power is one of the scenarios in which the links between enterprise, business and politics can best be observed. After the coming to power as provisional governor of Lorenzo Latorre in 1876, a year later a meeting took place that would further strengthen his authoritarian power in Uruguay, in which elite members of the country with direct participation in the local Montevideano power intervened: the Junta Económica Administrativa. With the use of notarial sources and commercial protocols, as well as information from the institution itself analysed, we identify who were those individuals and their relationships with municipal politics and business in Uruguayan militarism.
\end{abstract}

Keywords: enterprise, business, local power, Montevideo, Uruguay.

\section{Introducción}

Durante el siglo XIX, Uruguay fue un territorio convulso. De ahí que el escritor inglés de origen argentino Guillermo Enrique Hudson definiera la Banda Orien- 
tal como «la tierra purpúrea». Hudson (2018) escribió en 1885 una obra que fue reeditada en 1904 y ha continuado reeditándose hasta la actualidad. En ella se describe un escenario en el que los enfrentamientos entre bandos fueron la tónica habitual. Los orígenes de esta «convulsionada situación» desde tiempos coloniales, que siguieron con la independencia y el conflicto regional de la guerra Grande, han sido estudiados por Ana Frega (2009: 4; 2015: 74). Este contexto, especialmente beligerante durante el siglo XIX, tiene un breve período de relajación entre 1852 y el inicio de la guerra de la Triple Alianza, que permitió que se asentara una etapa precapitalista que estableció unas bases técnicas e institucionales del paisaje uruguayo y regional en general. Dicha situación, inscrita dentro del denominado «modelo agroexportador» o «modelo de crecimiento hacia fuera guiado por las exportaciones» (Delbono, 2007: 145), se basó en un proceso de acercamiento a los centros del capitalismo avanzado que veían en las economías de América Latina un mercado ideal para satisfacer «la demanda exportadora de bienes primarios de las potencias occidentales, erigiéndose a su vez como significativos receptores del excedente de producción manufacturada y la inversión de capitales extranjeros» (Ibídem: 144). Dentro de este contexto internacional, la producción de Uruguay se sustentaba sobre una ganadería tradicional que comenzó con una mestización del vacuno y del ovino, seguida de una agricultura poco explotada y dominada por la diversificación ganadera, que, con el paso de los años y la llegada de la inmigración europea, se expandió a nuevos cultivos y usos industriales y dio como resultado la aparición de nuevos actores económicos (Barrán y Nahum, 1967: 142; Beretta Curi, 2011: 43).

Esta inserción económica, tardía y totalmente dependiente de las fluctuaciones y crisis financieras o de comercio mundiales, hizo que el acatamiento a esas injerencias fuera total y produjese momentos de inestabilidad económica y política, como el de la Revolución de las Lanzas (1870-1872). Durante este conflicto, nació uno de los referentes económicos de Uruguay, la Asociación Rural (1871), institución que medió en la finalización del conflicto bélico, que se había iniciado meses atrás. Además, fue la promotora de una transformación del agro impulsada por «una activa élite» (Beretta Curi, 2011: 46). La debilidad institucional y administrativa del Estado, ya expuesta, se vio agravada con la crisis económica y financiera de 1875 -el llamado «año terrible» (Barrán, 1968: 22) - , ${ }^{1}$ que provocó el ascenso de la clase militar y del fenómeno estructural del militarismo en Uruguay, así como en el contexto regional latinoamericano (Girón, 1977).

A este proceso de integración se adhirieron los antiguos miembros de la sociedad tradicional uruguaya. De igual manera, las ideas liberales sustentadas en el librecambio y la libre empresa hicieron que los caminos políticos abiertos se uniesen al mundo empresarial local. Para W. Reyes Abadie y José C. Williman (1969: 23), «las primeras formas de acumulación de capital fueron mediante préstamos al Estado y el negociado de Deuda Pública; instalación de bancos

1. Hay que mencionar que la crisis de 1875 acontecida en Uruguay vendría como consecuencia de la crisis financiera mundial de 1873. Véase: Marichal (2009). 
estrechamente vinculada a la primera actividad; y, desde luego, la explotación pecuaria y el comercio exterior». En cierta medida, sería la inauguración de un capitalismo incipiente con unas características parejas al crony capitalism o «capitalismo de amigos». ${ }^{2}$ Por ejemplo, en 1865, bajo el gobierno del general Venancio Flores, se dictó el decreto-ley que organizaba el reglamento orgánico de bancos en suelo uruguayo de la mano del entonces ministro de Hacienda Tomás Villalba. Con esta norma se permitía la instalación de establecimientos de bancos de emisión, depósitos y descuentos, que favoreció el nacimiento de empresas financieras extranjeras, como fue el Banco de Londres y Río de la Plata. ${ }^{3}$ Esta llegada de capitales extranjeros, que se producía por la situación excepcional que vivía Montevideo como «plaza de abastecimiento» de las fuerzas brasileñas y orientales unidas a las argentinas contra Paraguay durante la guerra de la Triple Alianza (Ruigomez Gómez, 1988; Brezzo, 2004; Sansón Corbo, 2015), supuso la entrada de Uruguay en los mercados internacionales.

En este contexto, el análisis de las relaciones entre los integrantes del poder local montevideano y los emprendimientos que comenzaron a surgir en el Uruguay del libre cambio mostrará las incidencias acontecidas en este período convulso a través del estudio del grupo que permitió perpetuar la dictadura del gobernador provisorio Lorenzo Latorre en 1877. Este trabajo pretende demostrar, por un lado, la debilidad del poder del Estado y la influencia de las élites económicas locales a pesar del poder férreo de los militares; y, por otro, el enfrentamiento entre la administración local y el gobierno nacional a costa de los escasos recursos concedidos por el Ejecutivo a las corporaciones locales en un momento de desarrollo de las ciudades.

Por todo lo expuesto, el estudio de los participantes en la reunión de «amigos» - en clara alusión al crony capitalism - , invitados por Lorenzo Latorre a su casa en 1877, y de sus relaciones con el poder local de la capital uruguaya -la Junta Económica Administrativa - , junto con sus vínculos con el mundo empresarial, nos permitirá conocer el funcionamiento de la sociedad del momento. A lo largo del texto, se intentará dar respuesta a diversas preguntas concretas: ¿quiénes fueron estos personajes?, ¿en qué emprendimientos destacaron más?, ¿qué relación mantuvieron con el poder local? y ¿qué perfiles socioeconómicos y profesionales tuvieron?

Para tal fin, estudiaremos los gobiernos locales durante el período de 1865 a 1886 y analizaremos la importancia que tuvo en 1877 el grupo de apoyo a Lorenzo Latorre, quien fue el principal artífice y hacedor del afianzamiento del poder nacional en Uruguay en 1876. Esos años verán intensos movimientos económicos, sociales y políticos que permitirán comprobar el funcionamiento de una sociedad periférica en un contexto internacional. Durante el período que abarca la presente investigación, Lorenzo Latorre generó dinámicas con actores que le consolidaron en su posición a pesar de ser opositores a sus ideales partidistas.

2. Aunque es un concepto aplicable al siglo xx, podemos encontrar ciertas similitudes que nos permiten comprender el capitalismo y su influencia sobre la política (Galindo, 2017).

3. Para una mejor comprensión del sistema financiero uruguayo, véase: Jacob (1996). 
Esta forma de proceder le permitió perpetuarse durante varios años más en el poder y sentó las bases del Estado moderno uruguayo. De ahí que consideremos que el conocimiento de los miembros del citado grupo y de los intereses económicos y la participación política local será un aporte original y novedoso para la historiografía uruguaya del siglo XIX, ya que hasta el momento solamente se disponía de datos fragmentarios.

En primer lugar, se analizará la llegada de Lorenzo Latorre al poder mediante un estudio del militarismo y el grupo de apoyo dado al gobernador provisorio. En segundo lugar, nos centraremos en la institución municipal uruguaya a lo largo del siglo XIX y sus vínculos con los asistentes a la reunión de 1877. Por último, tras conocer el militarismo uruguayo, a sus actores y a la Junta Económica Administrativa, pondremos nuestra atención en las relaciones y vínculos empresariales del grupo estudiado para, finalmente, llegar a las conclusiones de la investigación, para la que se ha contado, entre otras fuentes, con documentos procedentes de archivos personales, protocolos judiciales y notariales, y prensa de la época.

\section{Inicios del militarismo en Montevideo y objeto de estudio}

Diez años después del decreto que organizaba el sistema financiero uruguayo en 1875 , tuvo lugar el motín militar que sentaría las bases del militarismo en Uruguay (Real de Azúa, 1969). Dicho evento desplazó a las autoridades civiles elegidas regularmente por un tímido militarismo mínimo, que pasó en 1876 a ser férreo de la mano de Lorenzo Latorre y de su sucesor, Máximo Santos (1880-1886). ${ }^{4}$ Para Barrán y Nahum, el militarismo sentó las bases definitivas del principio de autoridad, "creando una estructura de poder que fue, en esencia, la del Estado moderno y centralizado que el Uruguay sólo había conocido por aproximaciones, mas nunca por entero" (Barrán y Nahum, 1967: 165). Finalmente, de la mano de Lorenzo Latorre, se unificó el territorio oriental alrededor de la ciudad-puerto de Montevideo, una de las grandes aspiraciones del sector mercantil y terrateniente aglutinado en la Asociación Rural (Beretta Curi et al., 2004). De hecho, aunque la historiografía aborda el apoyo dado por varios sectores preeminentes al militar, se ha de destacar que, de forma oficial, fue solo un pequeño grupo social el que de forma tácita y oficial arropó a Latorre firmando un documento de apoyo, en 1876 (Talamante Pérez, 2020). ${ }^{5}$ Poco más de un año después, tras el fracaso de los comicios de 1877 - que, a pesar de las proclamas del gobernador, no se celebraron $-{ }^{6}$ tuvo lugar en la casa de Lorenzo Latorre un encuentro con una represen-

4. Para comprender la llegada al poder de Lorenzo Latorre y el grupo que lo apoyó en la reunión de 1876, véase: Talamante Pérez (2018a; 2018b; 2020).

5. La prensa de Montevideo de la época refleja los acontecimientos y expone en informaciones varias la lista de signatarios, como se observa en El Ferrocarril, 11 de marzo de 1876, pág. 3; La Tribuna, 12 de marzo de 1876, pág. 4; Orden Público, 12 de marzo de 1876, pág. 1; El Siglo, 13 de marzo de 1876, pág. 1; El Nacional, 13 de marzo de 1876, pág. 2.

6. En junio de 1876, cuando debían haber tenido lugar los comicios, el dictador envió misivas a todos los departamentos recomendando la perpetuación del sistema; se llegó a tal situación, que el propio gobernador provisorio se presentó en el Teatro Cibils ante sus seguidores y afirmó que lo 
tación de las figuras más relevantes del poder económico, social y político de Uruguay. Dicha reunión se celebraba para "cambiar ideas acerca de la situación" (Salterain y Herrera, 1975: 345). Pero en realidad el objetivo del encuentro era averiguar si convenía «o no al país la prórroga del gobierno provisorio en la persona del coronel Latorre; si conviene la convención nacional y en qué modo y tiempo debe entrarse en el camino constitucional» (Acevedo, 1945: 241).

Se trataba de una veintena de individuos ${ }^{7}$ que representaban lo más alto del comercio y de la sociedad uruguayos de la época. Tras un año de gobierno de Latorre, los avances acontecidos en la República bajo su mandato eran considerables en distintos ámbitos: redacción de un decreto-ley de educación común; ${ }^{8}$ aprobación de las Ilamadas Guías de Campaña; ${ }^{9}$ regulación de la exportación libre ${ }^{10}$ y las marcas de fábrica y de comercio; ${ }^{11}$ fundación de la Dirección y Administración General de Correos; ${ }^{12}$ elaboración de un nuevo Código Civil $^{13}$ y otro Penal; ${ }^{14}$ aprobación de decretos que regulaban la vida diaria de la República y que, en cierta medida, estructuraban y reorganizaban el nuevo modelo de país y de Estado. Sin embargo, a pesar de los avances acontecidos en este período, los aires cambiaban y la nota siguiente así lo reflejaba: «la política que ha inaugurado desde que asumió el mando de la República le ha granjeado algunas simpatías; pero dudamos que pueda mantenerlas vivas en el espíritu si no entra con más paso firme y franco en el camino de las reformas radicales». ${ }^{15}$

mejor era formar una Comisión Directiva que se encargara de «compulsar» las actas y peticiones para aplazar las mismas. La lista que se nombró para tal fin estaba formada por Lorenzo Batlle, Felipe Fraga, Mateo Magariños Cervantes, Juan Pedro Salvañach, José M. Vilaza, Carlos de Castro, Hipólito Gallinal, Laudelino Vázquez, Pedro Carvé, Dionisio Ramos, Félix Buxareo y Francisco Montero. Según la prensa, se votó por unanimidad y se decidió aplazar las elecciones hasta noviembre (fecha que, finalmente, tampoco fue válida), y se acabó provocando la segunda reunión que analizamos aquí. La Tribuna, Montevideo, 15 de junio de 1876, pág. 2.

7. Además de Lorenzo Latorre, los participantes en esta reunión fueron Lorenzo Batlle, Aurelio Berro, Eduardo Brito del Pino, Carlos de Castro, Federico Cibils, Hipólito Gallinal, Juan José de Herrera, Manuel Herrera y Obes, Juan D. Jackson, Mauricio Llamas, Eduardo MacEachen, Mateo Magariños Cervantes, Juan Miguel Martínez, Luis Eduardo Pérez, Pedro Piñeyrúa, Carlos Reyles, Laudelino Vázquez, Juan Vázquez Sagastume, Ernesto Velazco y Pedro Visca.

8. La comisión que estudió el proyecto estuvo conformada por varios miembros que formaron parte del grupo de apoyo a Latorre, como Alejandro Magariños Cervantes, Blas Vidal, Melitón González, Francisco de Acha, Juan Torres, Agustín de Castro y Jaime Roldós, y fue José Pedro Varela quien lo presentó a la cámara.

9. Se trató del Decreto-ley de 27 de septiembre de 1877, creado para evitar «abusos» y relativo a las «guías de campaña para el tránsito terrestre de mercaderías, frutos del país y ganados» (Alonso Criado, $1880: 85$ ).

10. El Decreto-ley de 24 de agosto de 1877 fue el más importante para el comercio que tuvo el apoyo de Latorre; según la medida, se dispuso que «toda clase de productos agrícolas o rurales, quedarán libres de todo derecho de Aduana a su exportación para puertos extranjeros", así que se eximió «todo derecho de exportación por mar a los ganados en pie que se embarcan para puertos extranjeros, sea con el objeto de exportarlos, sea para el consumo de los pasajeros y tripulación» (Ibídem: 671).

11. Decreto-ley de 1 de marzo de 1877 (Ibídem: 524).

12. Decreto-ley de 24 de agosto de 1877 (Ibídem: 646).

13. Decreto-ley de 9 de marzo de 1877 (Ibídem: 357).

14. En realidad, se nombró una comisión para la redacción del código (Ibídem: 186).

15. Periódico El Negro Timoteo, Montevideo, año I, núm. 8, 9 de abril de 1876, pág. 2. 
Es por ello que el gobernador invitó a su casa a esta representación de la sociedad uruguaya para valorar el apoyo con el que contaba en diciembre de 1877. La misiva se envió firmada de puño y letra por el propio Latorre, como la enviada a Hipólito Gallinal:

[Montevideo, 4 de diciembre de 1877] Gobernador Provisorio / Señor Dr. Don Hipolito Gallinal, Presente Muy Señor mío: En el deseo de aconsejar mi opinión sobre la solución de la cuestión política he creído oportuno convocar á una reunión de Ciudadanos. Siendo Vd uno de los designados con tal objeto, he de estimarle se digne concurrir á mi casa habitación, el Jueves 6 del corriente de 8 a 8 1⁄2 de la noche. Saludo a Vd att. S.S. L. Latorre Despacho Diciembre 4/1877. ${ }^{16}$

En el transcurrir de la reunión, observó y contó con el apoyo total de Pedro Visca, Laudelino Vázquez, Carlos de Castro y Mateo Magariños Cervantes, que defendieron y se mostraron a favor del mantenimiento de la dictadura. En cierta medida, el apoyo de Castro era esperable, ya que este había visto aumentado el volumen de sus negocios financieros y la compraventa durante estos meses; también parecía obvio el de Mateo Magariños, que deseaba obtener una licencia para abrir una línea de tranvía en la capital (Talamante Pérez, 2018a). El caso de Castro fue más patente, ya que este se hizo acreedor de Juan Enrique Mackinon por un importe de 1.915 libras,${ }^{17}$ participó del concurso de acreedores de Carlos Márquez por un importe de 10.000 pesos que cedió a su hermano Agustín de Castro, ${ }^{18}$ y compró un préstamo que otro de sus hermanos, Juan Pedro de Castro, tenía con el Gobierno de la República proveniente de indemnizaciones de ganado lanar que fue tomado para consumo de ejércitos del país, y que posteriormente vendió al Banco Mauá por el precio de 132.723 pesos, recibidos antes de la firma de dicha transacción. ${ }^{19}$

Vázquez Sagastume, en cambio, mostró sus recelos a mantener el gobierno provisorio bajo la tutela de Lorenzo Latorre, pero finalmente ofreció su apoyo al mantenimiento de la dictadura por dos años con la condición de que luego se volviera al «régimen constitucional» (Acevedo, 1945). Y Aurelio Berro no se decantaba por un apoyo a ultranza ni una rotura del sistema vigente, pero deseaba, al igual que Sagastume, «el restablecimiento del régimen constitucional». En esta línea, también se encontraban Manuel Herrera y Obes y Juan José de Herrera. ${ }^{20}$ En una postura contraria se hallaban Mauricio Llamas y Eduardo Brito del Pino, que deseaban la pronta llegada a una situación constitucional. Tras escuchar todas las

16. Carta de Lorenzo Latorre a Hipólito Gallinal para convocarle a la reunión de ciudadanos para solicitarles su opinión sobre una cuestión política. Archivo Museo Nacional, Carpeta Lorenzo Latorre, Caja 517.

17. Escribano J. L. Antuña, en Archivo General de la Nación (en adelante AGN). Escribanía de Comercio, Protocolo 86, 12 de junio de 1876.

18. Escribano J. L. Antuña, en AGN. Escribanía de Comercio, Protocolo 210, 23 de noviembre de 1876.

19. Escribano Carlos Casaravilla, Archivo Poder Judicial (en adelante APJ). Protocolo 394, 22 de noviembre de 1876.

20. La dirección de El Siglo, en su edición del 24 de noviembre de 1877, se sorprendía de la participación de Herrera en la reunión que perpetuaba el gobierno de Latorre y de la que salió elegido para el Consejo Consultivo que debía encargarse de la realización de los comicios de 1878. 
semblanzas presentes, el propio Latorre propuso la «prórroga de la dictadura por un año, realizándose los comicios al finalizar ese año», así como el nombramiento entre los ciudadanos allí presentes de un consejo consultivo que redactaría un proyecto de ley para las elecciones. Este consejo (figura 1) contó con juristas relevantes del Uruguay de la época que asistieron al encuentro, así como con la presencia de representantes de ambos partidos tradicionales.

Figura 1. Lista de ciudadanos para Consejo Consultivo.

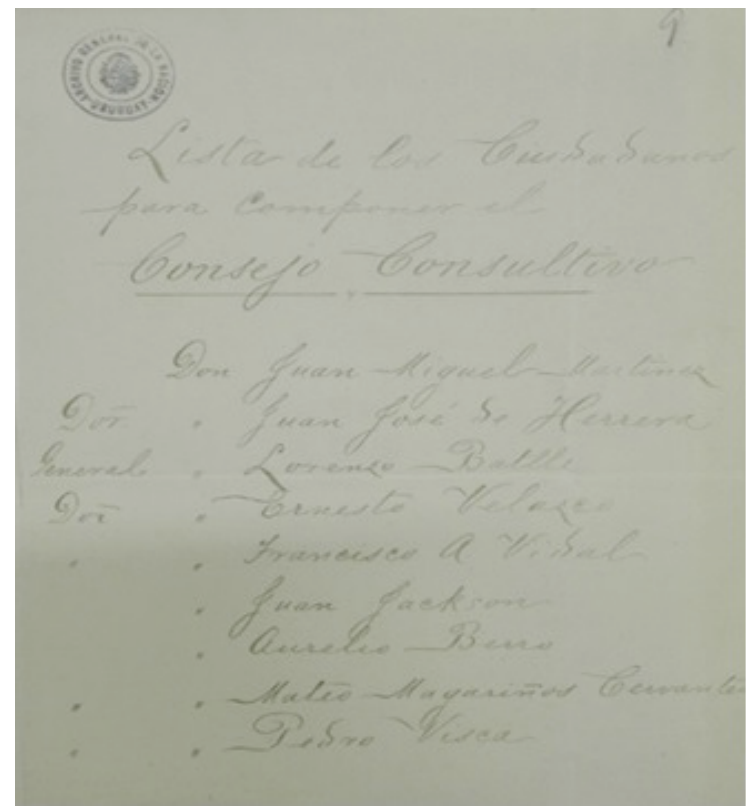

Fuente: AGN. Fondo Particulares, caja 112, carpeta 12, Archivo de Mateo Magariños Cervantes. Correspondencia con el General Lorenzo Latorre, 1876-1878, doc. 9.

En cierta medida, estos individuos fueron los que por mediación de sus apoyos y decisiones marcaron el desarrollo de la dictadura y el proceder de Lorenzo Latorre en sus últimos años de gobierno. Es decir, con el beneplácito para continuar con el sistema dictatorial dado al gobernador provisorio en la reunión celebrada en 1877 se aceptaba la transformación del aparato burocrático en beneficio del militar.

En suma, y a tenor de las posturas mostradas y de los negocios desarrollados, podría traslucirse el interés de los protagonistas y defensores de la continuación de la dictadura. Es por esta razón que conocer el perfil social, político y económico del segundo grupo de apoyo al gobernador provisorio mostrará las realidades de la sociedad montevideana en un contexto internacional. 


\section{Análisis social del grupo de apoyo a Lorenzo Latorre en 1877}

A pesar de que el período del militarismo ha sido un tema muy recurrente en la historiografía uruguaya, el desconocimiento acerca de quiénes fueron los participantes en dicha reunión es sorpresivo. Por eso mismo, un análisis microhistórico de este espacio social permitirá conocer el capital relacional y los vínculos más reseñables del grupo que marcó un momento concreto de la sociedad uruguaya. ${ }^{21}$ A continuación, abordaremos los aspectos más relevantes de la muestra estudiada, señalando año y lugares de nacimiento, estudios, lazos comerciales y vínculos profesionales para sopesar la impronta del análisis.

Para comenzar, de los veinte individuos que participaron en la reunión de 1877, doce de ellos $(58,34 \%)$ cumplieron con funciones en la administración - profesores de universidad, agentes fiscales, jueces, etc. - , a los que se podrían añadir dos más que ejercieron sus funciones en la institución militar (gráfico 1). Este dato haría subir la muestra hasta el 63,63\%, una información muy relevante para comprender el funcionamiento de la estructura que estamos analizando, ya que confirma la dinámica de las élites de poder que coparon el aparato burocrático del Uruguay de mediados del XIX. Varios de esos actores con funciones públicas compartieron diversas actividades profesionales y sociales y establecieron vínculos que les permitieron ostentar poder e influencia en las redes clientelares en las que participaron; además, en el caso que estudiamos, todos ellos descendían del antiguo patriciado o de familias acaudaladas del Uruguay de la época. Este dato nos permite señalar que Lorenzo Latorre debió de contar con un apoyo más amplio y relevante en relación con los que firmaron en marzo de 1876 el manifiesto que le encumbró y le mantuvo en la presidencia la República. ${ }^{22}$ Pedro Visca -médico - y Laudelino Vázquez - abogado - participaron en las dos reuniones, lo que refleja la impronta de ambos individuos dentro del círculo de Lorenzo Latorre.

Gráfico 1. Profesiones de los actores de la reunión de 1877.

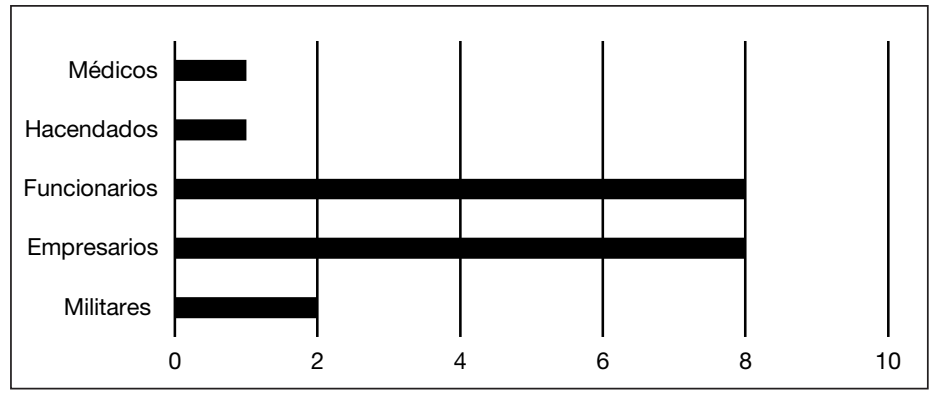

Fuente: Elaboración propia, en Talamante Pérez (2019: 137).

21. Para saber más sobre la historia social y el análisis microhistórico, véanse: Burke (1993), Levi (1985) y Revel (1996).

22. Para una mejor comprensión del grupo de signatarios de Lorenzo Latorre en 1876, véase: Talamante Pérez (2020). 
A continuación presentamos a algunos de los actores participantes en la reunión de 1877. Uno, Ernesto Velazco, comienza como fiscal, sigue luego como miembro de la Junta de Crédito Público y, finalmente, es ministro de Relaciones Exteriores bajo las presidencias de Lorenzo Batlle ${ }^{23}$ y de Tomás Gomensoro. ${ }^{24}$ Otro, Vázquez Sagastume, desarrolló la mayor parte de su carrera pública en el Ministerio de Relaciones Exteriores, aunque también ejerció como fiscal de lo Civil durante varios años.

Otros miembros fueron Federico Cibils y Carlos de Castro. El primero, miembro de la Junta de Montevideo que formó parte de la Comisión Nacional de Caridad, ocupó la Secretaría de Aduana del Puerto; el segundo cumplió funciones en la administración judicial del Estado y en la Universidad, llegó a ser diputado y senador y alcanzó sus cargos más importante con Venancio Flores, ${ }^{25}$ como ministro de Relaciones Exteriores, y bajo la presidencia de Máximo Santos, ${ }^{26} \mathrm{co}-$ mandando el Ministerio de Gobierno tras la marcha de Latorre y el primer interinato de Francisco Vidal. ${ }^{27}$

Asimismo, lo clarificador de esta estructura es que se podría decir que sus miembros componían una élite política, ya que, excepto Mauricio Llamas, del cual no tenemos constancia alguna, los 19 restantes se sentaron en las bancas del Parlamento - como diputados o senadores - o en las de la Junta Departamental de Montevideo, lo que nos muestra claramente la relevancia política del grupo analizado. A esto debemos añadir la particularidad de que el $26 \%$ de ellos había compaginado las tareas de senador o de diputado por Montevideo u otro departamento de la República. Este dato se magnifica cuando se relaciona el poder nacional con el ejecutivo, puesto que el $54 \%$ había desempeñado funciones en algún ministerio o en alguna de las áreas de la política nacional, lo que refleja la preeminencia y el capital social de los presentes en la reunión en la casa de Lorenzo Latorre. Además, nos encontramos con dos actores que a lo largo de su carrera ostentaron el honor de ser presidentes de la República, como son Lorenzo Batlle y Eduardo Mac-Eachen (Rodríguez Ayçaguer, 2010), lo que certifica, nuevamente, la relevancia de la muestra analizada.

Para concluir con los vínculos de la política y los miembros estudiados, voy a referirme a una figura fundamental durante el siglo XIX que se ha trabajado en España de forma exhaustiva y en menor medida en América Latina: el cunero. ${ }^{28}$ Una práctica política y habitual en la península ibérica, y que como se puede

23. Presidente de la octava legislatura (1/3/1868-1/3/1872).

24. Presidente de la novena legislatura (1/3/1873-22/1/1875).

25. Presidente de la sexta legislatura (20/2/1865-15/2/1868).

26. Presidente de la decimotercera legislatura (1/3/1882-1/3/1886).

27. Francisco Vidal ostentó en dos ocasiones la presidencia de la República, en la decimosegunda y en la decimocuarta legislatura. Los períodos comprenden el período 1880-1882 y el año 1886.

28. Según el diccionario de la Real Academia Española, el cunero es el candidato que se presenta a las elecciones por un territorio o distrito distinto al que pertenece, patrocinado por el Gobierno. Esta figura ha sido trabajada, en el caso español, por Forner et al. (1990), Peñarrubia (1982) y Sagrado Domenech (2015); y, en el caso latinoamericano, por: Benito Sánchez (2008) y Núñez García (2010), entre otros autores. 
observar en la muestra que analizamos, podría ser una figura incipiente e interesante de abordar desde este prisma histórico y conceptual. Además, en Uruguay encontramos tensiones políticas del tipo centro-periferia durante toda la segunda mitad del XIX, merced a las comunicaciones y medidas que desde Montevideo se hacían con el resto del país. En cierta medida, esta situación venía desde la colonia, ya que los centros urbanos no estaban comunicados entre sí, y el litoral lo estaba por vía fluvial, con lo que nada había cambiado en años y el futuro marcaría un entramado de comunicaciones centrado en una estructura radial con centro en Montevideo (Rial et al., 1981). Asimismo, y dentro de esta línea, el retraso en cuanto a las comunicaciones hacía que unas zonas se desarrollaran más que otras. Además, en todo este entramado, «se seguían manteniendo los mismos rumbos coloniales con un sistema de chasques para la correspondencia oficial, uno de diligencias y postas", que eran de difícil mantenimiento para los concesionarios, y estos veían imposible desarrollar su actividad en igualdad de condiciones que sus otros vecinos que empezaban a tener ferrocarril, telégrafo, navegación u otras formas de comunicación. Esta situación, unida al conflicto entre los representantes profesionales y los poderes locales, provocó cierto desasosiego entre las gentes del interior, porque se imponían dichos políticos desde Montevideo y los problemas reales del interior acababan en total abandono. Es significativo este dato, puesto que, de la veintena de actores estudiados, 17 son de Montevideo y todos representan a otros departamentos a lo largo de su carrera política e incluso a varias regiones: por ejemplo, Manuel Herrera y Obes era diputado por Paysandú y Montevideo y posteriormente sería senador por Durazno y Colonia (gráfico 2). Esto certifica el retroceso que vivió el interior en este período y que permitió la tensión vivida entre «la capital y un interior relegado» (Rial et al., 1981: 46).

Gráfico 2. Origen de los participantes (1877).

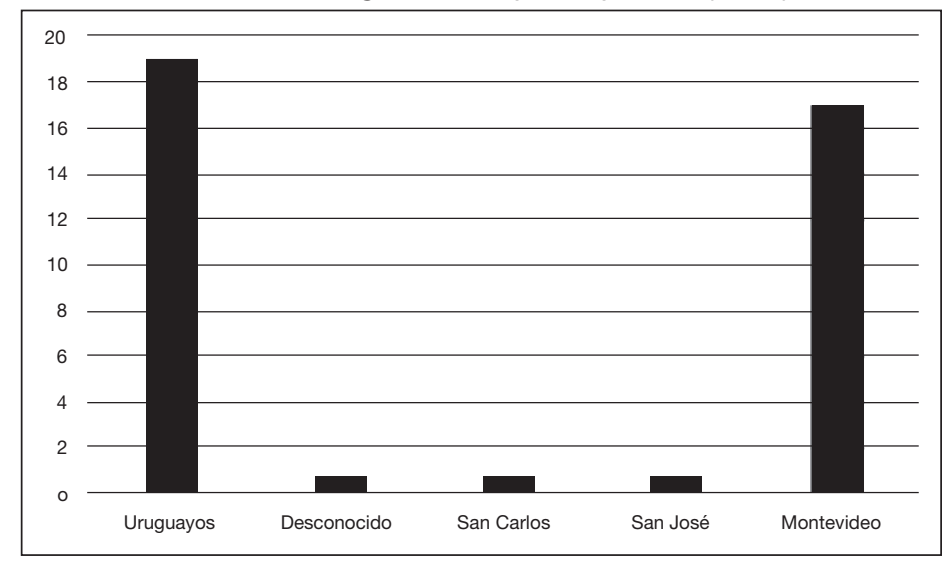

Fuente: Elaboración propia, en Talamante Pérez (2019: 140).

Siguiendo con lo que hemos planteado con anterioridad, hemos de reseñar el lugar de nacimiento de los 20 asistentes a la reunión convocada por Lorenzo 
Latorre (gráfico 2). A diferencia de los que participaron en la reunión de 1876, en la que se encontraban un número considerable de extranjeros, en la de 1877 todos eran exclusivamente uruguayos. Además, 17 habían nacido en la capital y uno, en la cercana San José, lo que muestra claramente la preeminencia del poder de Montevideo con respecto al interior y el enfrentamiento entre la ciudad y la campaña a lo largo de la historia uruguaya. En suma, la influencia del poder montevideano se refleja en los datos geográficos de los que apoyaron a Latorre tras esta segunda reunión, y la configuración de sus miembros muestra la impronta del capital social y político de la capital con relación al litoral y el interior del Uruguay. Al igual que en la reunión de 1876, en la que la afinidad colorada era la predominante, en la de 1877 la presencia colorada también es mayoritaria. Es decir, de los asistentes, el $50 \%$ pertenecen a las líneas coloradas, mientras que siete (35\%) defienden la divisa blanca. Aunque tienen una acción pública más activa, desconocemos la afinidad política de tres de ellos (15\%): Ernesto Velazco - ministro de Relaciones Exteriores con Batlle y de tendencia colorada-, y Pedro Piñeyrúa y Federico Cibils - que actúan en la Junta Económica Administrativa de Montevideo- . Los actores analizados desarrollaron estudios que les permitieron llegar a estas posiciones y cargos (gráfico 3). El 57\% cursaron leyes y una parte de ellos (cinco sobre once) alcanzaron el doctorado e incluso obtuvieron una cátedra universitaria, como son los casos de Eduardo Brito del Pino y Laudelino Vázquez.

Gráfico 3. Estudios de los participantes en la segunda reunión (1877).

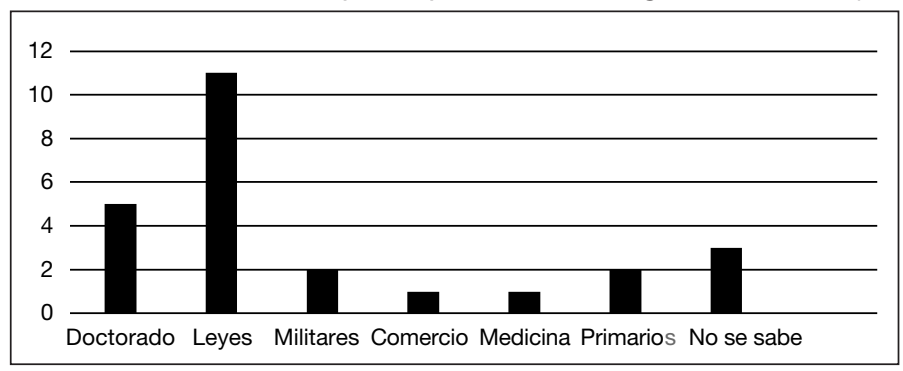

Fuente: Elaboración propia, en Talamante Pérez (2019: 141).

Dos de los miembros solo cursaron estudios primarios y otros dos eran militares; y nos encontramos también con tres que contaban con estudios de comercio y medicina, y de uno tenemos constancia de que había cursado estudios superiores, aunque ignoramos de qué tipo; igualmente desconocemos la formación de otros tres (gráfico 3).

Para terminar de comprender el funcionamiento y estructura del grupo conformado por los integrantes de la segunda reunión, creemos oportuno ofrecer los datos relativos a los nacimientos y en las épocas en los que suceden, ya que, dependiendo de los mismos, y a tenor de la fecha de la reunión estudiada, hemos podido comprobar la eventual relación entre la edad y la carrera pública (gráfico 4). Sobre este particular sabemos que la media de edad de los participantes en la asamblea de 1877 superaba la cuarentena y se encontraban en su cenit político. El caso más significativo es el de Juan Miguel Martínez, que, con 
72 años, es el más anciano y que participó, junto con Atanasio Aguirre y Francisco Lecocq, en diversos negocios destinados a la cría de animales finos y gusanos de seda y en ensayos industriales modernos.

Gráfico 4. Fecha de nacimiento de los actores (1877). ${ }^{29}$

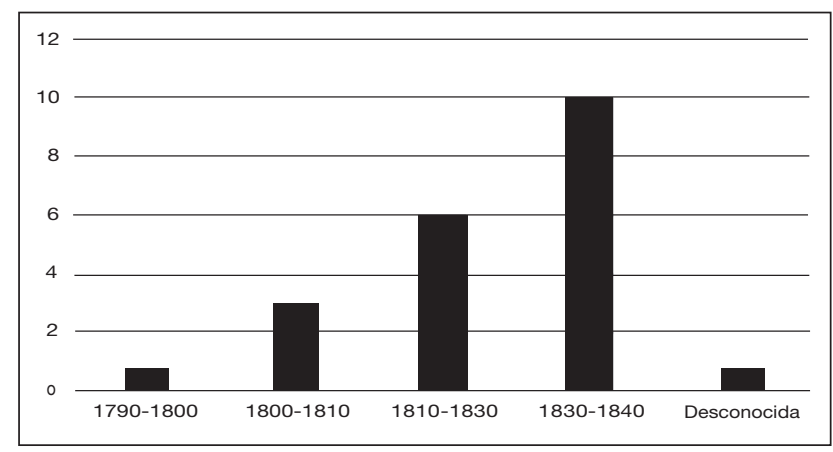

Fuente: Elaboración propia, en Talamante Pérez (2019: 142).

Una particularidad es que el más anciano y el más joven de la reunión distan, en edad, cincuenta años. Y también resulta llamativo el hecho de que la mayoría nacen ya con la creación del Estado del Uruguay y que muchos son hijos de personajes relevantes de la Independencia o que tienen algún parentesco con los mismos. Nacen en su mayoría en un período de fusión tras la guerra Grande, y aunque ese espíritu esté presente las divisas marcan el carácter de estos a lo largo de sus carreras públicas y burocráticas.

Otro de los aspectos interesantes para visualizar la importancia y relevancia de los integrantes de la reunión analizada es el relativo a su capital económico. Para tal fin, se ha tomado como referencia la información de un documento de la Colecturía General para el pago de impuestos del año 1875, conocido también como el «año terrible» (Barrán, 1969). El documento en cuestión es la Relación nominal de los declarantes en la Oficina de Contribución Directa de la capital y departamentos en el que se refleja la preeminencia de los participantes en aquella reunión (cuadro 1). Esta fuente contabiliza un capital de 100.461.362 pesos como entrada de impuestos de la contribución directa en el Departamento de Montevideo, que aglutinaba la declaración de fincas urbanas y rústicas; terrenos de labranza; capitales en giro; animales vacunos, yeguarizos, etc., así como la regularización de los impuestos de años anteriores. Bajo este panorama, se contabilizan un total de 7.408 entradas de pagos al Estado, en las que cada ciudadano o ciudadana pagaba, en una o varias ocasiones, con un total de 401.855 pesos que entraban en las arcas públicas por parte de la capital uruguaya. Y para el resto del país se recaudaron 434.804 pesos sobre un capital de 102.160 .835 pesos que estaban en

29. Contamos con datos de 19 de los 20 integrantes de la asamblea de 1877 . No poseemos información relativa a Pedro Piñeyrúa. 
manos de particulares y empresas asentados en Uruguay. Las cuotas cobradas por el fisco se hacían al 4\%, si correspondían al año en curso, o al 4,5\%, si correspondían a una regularización de años anteriores. El total del capital de Uruguay para el año 1875 era de 202.622.197 pesos. Por tanto, la capital y la campaña en relación con la riqueza del país tenían prácticamente el mismo peso. Debemos destacar que los departamentos con más patrimonio del territorio en ese momento eran el de Montevideo - algo lógico y normal - , Paysandú (15.680.690 pesos), Salto (14.163.715 pesos), Canelones (11.868.555 pesos) y Tacuarembó (10.180.619 pesos); y San José, La Florida, Durazno, Soriano, Cerro Largo, Maldonado y Minas quedan con capitales inferiores a 10 millones de pesos.

En el cuadro 1, observamos que 14 de los 20 invitados a la reunión declaran en 1875. Son relevantes los capitales de Carlos Reyles y Juan Dámaso Jackson, con más de 300.000 pesos uruguayos. En el extremo contrario se halla Eduardo Brito del Pino, con solo 600 pesos y un pago de 2,4 pesos a las arcas del Estado. Nos faltan en esta declaración seis de ellos, de los cuales, aunque no declarasen en ese año, nos constan sus negocios e influencia política, social y económica. Además, aparecen en muchas ocasiones con varias entradas, lo que hacía interesante el incesante movimiento comercial en el que estaban asentados. Significativo era el caso de Aurelio Berro, que declara como particular y como titular de la sociedad Aurelio Berro y Cía.; y el de Duncan Stewart, con su empresa Courras Stewart. Además, otro dato significativo es que algunos de estos actores declaran en varios departamentos su capital: por ejemplo, Carlos Reyles, Eduardo Mac-Eachen, Hipólito Gallinal, Juan Miguel Martínez, Luis Eduardo Pérez, Manuel Herrera y Obes y Mauricio Llamas (en dos), así como Juan D. Jackson (en tres departamentos), lo que certifica la diversidad de las inversiones y rubros de cada uno de los participantes en la reunión.

Cuadro 1. Capitales declarados y pago de impuestos en 1875 (en pesos).

\begin{tabular}{|l|c|c|}
\hline \multicolumn{1}{|c|}{ Participante reunión } & Capital & Pagado \\
\hline Aurelio Berro y Aurelio Berro y Cía & 101.000 & 404 \\
\hline Carlos Reyles & 310.232 & 360 \\
\hline Eduardo Brito del Pino & 600 & 2,4 \\
\hline Eduardo Mac-Eachen & 114.921 & 351,65 \\
\hline Federico Cibils & 82.000 & 328 \\
\hline Hipólito Gallinal & 17.000 & 248 \\
\hline Juan Dámaso Jackson & 394.122 & $1.536,49$ \\
\hline Juan Miguel Martínez & 30.000 & 118 \\
\hline Laudelino Vázquez & 14.000 & 56 \\
\hline Luis Eduardo Pérez & 9.657 & 38,63 \\
\hline Manuel Herrera y Obes & 132.500 & 530 \\
\hline Mateo Magariños Cervantes & 42.000 & 168 \\
\hline Mauricio Llamas & 101.500 & 404 \\
\hline Pedro Piñeyrúa & 112.500 & 450 \\
\hline
\end{tabular}

Fuente: Elaboración propia a partir de Relación nominal de los (...), 1875. 


\section{Relaciones de negocios y poder local en la Junta Económica Administrativa de Montevideo}

Se ha reseñado y destacado el rol predominante de Montevideo con respecto a otras regiones del país, con lo que creemos oportuno citar la participación de dichos protagonistas en la vida política local montevideana con relación a su integración o no en la Junta Económica Administrativa o su nombramiento como jefe político de la capital. ${ }^{30}$ Lorenzo Latorre se encontró con el complicado funcionamiento de los poderes locales que ya recogía la Constitución de 1830 bajo la denominación de Juntas Económicas Administrativas, continuadoras de los antiguos cabildos, eliminados en 1826. Estos nuevos órganos creados por el nuevo Estado debían velar por la seguridad de los ciudadanos - mediante el control policial, el sorteo de milicias, las listas de jurados, la seguridad en las cárceles, etc.-, así como por la recaudación y repartición de impuestos, la fiabilidad de las pesas y medidas, y el cuidado de la salud de los habitantes de los municipios. En general, debían desempeñar tantas funciones que, desde un principio, resultaban demasiadas, a tenor de los recursos existentes. Sin embargo, no fue hasta 1832 cuando desde la capital montevideana se exigió una ley reguladora que controlara realmente la realidad de la gestión de estas instituciones. La iniciativa quedó aparcada a causa de los conflictos bélicos y no fue hasta 1861, con Bernardo Berro en la presidencia, que se retomó el impulso para darle a estas entidades funciones propias. Asimismo, bajo la presidencia de Gabriel Antonio Pereira, se les amplió el espectro de atribuciones para, así, obtener en cierta medida un desarrollo de los intereses locales.

La Junta de Montevideo, al ser la más relevante en el país, tuvo que desarrollar más tareas administrativas que ninguna otra; además, se le unía el deseo de descentralización de ciertas áreas en clara sintonía con las palabras de los primeros constituyentes, cuando idearon el marco legal del poder local uruguayo. De hecho, según un escrito de 1860, se defendía el instinto social y los intereses comunes de los que vivían en el mismo suelo, en clara alusión a la institución municipal, la cual definían como el «anillo que liga la familia al Estado», lo cual certifica el valor que desde algunos sectores se le daba a este ente (Memoria de la JEA, 1860: IV). ${ }^{31}$

En el caso que nos toca, en Montevideo, encontramos también comisiones auxiliares que gestionaban los nuevos municipios que se iban creando con la expansión y los períodos de especulación inmobiliaria. La primera fue la de La Unión, en 1864; y le siguieron la de Pando, la de La Aguada y otras. De todas for-

30. Para realizar este análisis, véase: Cheroni (1966) y Talamante Pérez (2018b).

31. De hecho, no fue hasta 1903 cuando se aprobó un proyecto de ley municipal que apareció en 1899 por una iniciativa popular y fue apoyado por el diario El Siglo. Dicha ley de 1903 fue nuevamente promulgada en 1909, con lo que se asentarían finalmente las bases del gobierno municipal, al cual se atribuirían tareas de gestión de agricultura y mejoramiento de la ganadería, así como de garantizar la prosperidad del departamento, velar por la educación primaria y los derechos individuales, otorgar concesiones de tranvías y transportes, y un largo etcétera, que solucionó, en cierta medida, unos vacíos de gestión heredados desde tiempos de la colonia. 
mas, los problemas que desde 1830 padecían estas entidades eran de carácter económico, ya que los ingresos que desde el poder ejecutivo se les asignaba eran «insuficientes y completamente aleatorios, puesto que pueden desaparecer de un momento a otro, en virtud de la derogación de las leyes o decretos que los crearon» (Acevedo, 1881: 23). Ante este panorama, Lorenzo Latorre se encontró una situación de bicefalia en lo que al poder se refiere. Hechas estas consideraciones, analicemos la relación del poder local y el grupo conformado por los participantes en la reunión de 1877.

Para empezar, seis de los integrantes del evento ocupaban o habían ocupado la bancada local de la Junta Departamental de Montevideo: Juan Dámaso Jackson había actuado como vocal (1857-1861); Juan Miguel Martínez, como vicepresidente (1865-1868); Duncan Stewart (1868), Manuel Herrera y Obes (1868-1870) y Luis Eduardo Pérez, como presidentes (1878-1879); y Federico Cibils, como vocal y como vocal suplente (1878-1879). Asimismo, encontramos a familiares directos de los participantes ocupando otros puestos, como Mariano Berro (jefe político), Agustín de Castro (presidente) y Francisco Magariños Cervantes (secretario). La relevancia y el peso de la familia certifica la impronta de los individuos. La muestra puede parecer escasa, pero el rol que juegan estos individuos en el contexto local se puede comprobar por la pertinencia de los recursos movilizados o que podían movilizar dependiendo de la situación, y en este caso fueron personas influyentes del Montevideo de la época.

Dentro de este juego de poder local, empresa y familia, tenemos a Carlos S. Viana, presidente de la Junta en el período 1871-1878. Dicho individuo, aunque no estuvo presente en la reunión de 1877, participó y firmó el manifiesto de apoyo a Lorenzo Latorre un año antes. Es interesante que, en dicha fecha, se otorgó a Eduardo Jackson - primo de Juan Dámaso Jackson - la concesión a diez años para poner avisos con letras transparentes en los faroles del alumbrado público y con la obligación de poner en los faroles de las esquinas el nombre de las calles y el de las oficinas públicas, propuesta que se elevó al Gobierno para su aprobación. ${ }^{32}$ Este hecho muestra las relaciones entre el poder local, el poder nacional y los negocios en el Uruguay del militarismo. Hay que tener en cuenta que los actores locales que aquí tratamos actúan no solo sobre un territorio, sino también sobre un contexto más global.

Asimismo, otra característica y cohesión de este grupo es que once de los participantes en la reunión (55\%) tienen negocios con la administración pública y el Estado. Por ejemplo, Carlos Reyles, Eduardo Brito del Pino y Juan José de Herrera destacan con varias operaciones de compra de tierras fiscales. Asimismo, el suministro o servicios al Estado reporta negocios a Mauricio Llamas, Mateo Magariños Cervantes, José Vázquez Sagastume y Federico Cibils. Y al ser prestamistas del Estado, Pedro Piñeyrúa, Mauricio Llamas, Manuel Herrera y Obes y Juan Dámaso Jackson fueron, sobre todo estos últimos, verdaderos apoyos económicos del militarismo. Hay que decir, que el Banco Comercial es-

32. Escribanía de Gobierno y Hacienda, en AGN. Protocolo 62, 15 de noviembre de 1876, pág. 165. 
tuvo muy bien representado en la reunión, ya que tanto Juan Miguel Martínez como Juan Dámaso Jackson fueron presidentes de dicha sociedad entre 1879 y 1892 (Banco Comercial, 1957). Y estuvieron presentes en los diversos directorios desde su fundación Jaime Cibils - padre de Federico Cibils -, Hipólito Gallinal, Eduardo Mac-Eacheno y Gualberto Méndez, que firmó el documento de apoyo a Lorenzo Latorre en 1876. Además del negocio financiero, el de suministros al Estado o a la administración, estaría el del transporte. Por ejemplo, con la expansión inmobiliaria y la ampliación de Montevideo, es necesario nutrir el país de comunicaciones que unan los nuevos barrios. Para ello, se creó una red de tranvías de tracción animal muy relevante en el perímetro y en el interior de la ciudad. De hecho, Juan Miguel Martínez, Aurelio Berro, Pedro Piñeyrúa, Mauricio Llamas, Mateo Magariños Cervantes y Juan José de Herrera intervienen en estos negocios y, a la vez, tienen participación directa en la gestión municipal, lo que demuestra los vínculos entre la empresa, los negocios y el poder político local y nacional en el Uruguay de la época. Los juegos entrelazados entre la política y la empresa se insertan dentro de las redes y relaciones sociales, verdaderas fuentes de oportunidades (Burt, 2005: 111) y juegan un rol esencial para el desarrollo de las empresas en todo proceso y sociedad (Comet, 2007).

Otro ejemplo reseñable fue Lorenzo Batlle, que, dentro del marco de sus relaciones e influencia en la vida política del Uruguay, desarrolló negocios con la Junta. Cedió un terreno en favor de la Comisión Extraordinaria Administrativa del Departamento de Montevideo en la zona de La Aguada, ${ }^{33}$ una comisión que estaba presidida en ese momento por Agustín de Castro, que recibió la oferta de cesión de terrenos propiedad de Batlle para poder abrir la calle que se «debe abrir en frente de la casa de Diego Novoa" y que la Junta pudiese empedrar dicha zona. Esta cesión debía cumplir una exigencia por parte de la administración, la cual Batlle exigió: "que no se me obligue a derrivar los alambres que quedan en parte en la calle». Tras el visto bueno, la Junta abonaría dicha cesión por la suma de 1.991 pesos. ${ }^{34}$

Para concluir con este apartado, hay que señalar que el hijo de Ernesto Velazco, Jaime Velazco, obtuvo una concesión por parte del Superior Gobierno para confeccionar y suministrar 2.256 uniformes destinados al personal de las Policías Urbanas y Suburbanas, Batallón Urbano, Escuadrón de Seguridad de la capital uruguaya. ${ }^{35} \mathrm{Y}$ dentro del negocio de suministros para el Estado, encontramos vínculos con la familia, como Francisco Magariños Cervantes, hermano de Matero Magariños, que obtuvo un contrato para proveer de víveres a todas las fuerzas movilizadas en el territorio de la República. ${ }^{36}$ En resumidas cuentas, todo un negocio que unía el poder local y nacional con el Estado mediante el establecimiento de lazos empresariales y políticos afines entre los actores involucrados, que nos muestran una realidad centrada en la reconstrucción de las es-

33. Escribanía de Gobierno y Hacienda, en AGN. Protocolo 264, 20 de diciembre de 1866, pág. 243. 34. Ídem.

35. Escribanía de Gobierno y Hacienda, en AGN. Protocolo 70, 4 de noviembre de 1898, pág. 204. 36. Escribano Alonso M. R., en APJ, Protocolo 226, 4 de septiembre de 1875. 
calas configuracionales que permiten una articulación de la periferia dominada por el centro o la capital, como es el caso de Montevideo.

\section{Conclusiones}

Para Swedberg (1997), la impronta de las redes y relaciones sociales en los mercados es tal, que afirma que es una de las causas de la aparición de las actividades económicas. La realidad mostrada en estas líneas podría certificar dichas palabras, ya que, en cierta medida, de las relaciones políticas surgen diferentes ideas de negocio en las que participan los individuos que están insertos en las relaciones y redes que las tejen. Además, se ha comprobado que muchos de los participantes en la reunión política que afianza el militarismo en Uruguay, celebrada en 1877 en la casa de Lorenzo Latorre, tenían intereses económicos que requerían que la situación continuase como estaba durante un tiempo. En cierta medida, podríamos decir que el interés público estuvo supeditado al interés particular de algunos actores en determinados momentos. Con este trabajo quedan demostrados los lazos y las relaciones entre el poder político, el económico y los negocios, y se ha corroborado el valor simbólico de los asistentes a la reunión de 1877 que permitió mantenerse en el poder a Lorenzo Latorre durante unos años más. De igual forma, se ha puesto en valor el rol jugado por estos individuos, que, aunque son conocidos en la historiografía uruguaya, no se habían estudiado desde una visión más global que describiera alguna acción política concreta de las que realizaron. Además, tras este análisis, se abren distintas posibilidades futuras, ya que a partir de ahora se pueden desarrollar otros estudios comparativos y de participación en la vida política y económica del Uruguay de la época.

Observamos que, tanto en los directorios de las empresas, como en las bancadas políticas o en la vida social uruguaya del momento, se intercambiaron recursos que permitieron a los diversos protagonistas coincidir en otras esferas $u$ otros espacios de interacción, y sería interesante analizarlos en el futuro.

El estudio realizado nos permite acercarnos a la realidad de las relaciones tradicionales de Uruguay de grupos altamente cohesionados que controlaron o dirigieron la vida económica, empresarial y política del Uruguay de finales del siglo XIX.

\section{Bibliografía}

AcEvedo, Eduardo (1881). El gobierno municipal. Montevideo: Casa A. Barreiro y Ramos. AcEvedo, Eduardo (1945). Anales históricos del Uruguay. Tomo Iv. Montevideo: Casa A. Barreiro y Ramos.

BARRÁn, José Pedro (1969). Latorre y el Estado uruguayo, Enciclopedia uruguaya. Historia ilustrada de la civilización uruguaya, t. 3, núm. 22. Montevideo: Arca. Disponible en http://www.periodicas.edu.uy/o/Enciclopedia_uruguaya/pdfs/Enciclopedia_uruguaya_ 22.pdf. 
BARRÁN, José Pedro y NAHUm, Benjamín (1967). Historia rural del Uruguay moderno, 18511885. Montevideo: Ediciones de la Banda Oriental.

BENITO SÁNCHEZ, Ana Belén (2008). "Determinantes institucionales de la reivindicación autonomista en Puerto Rico». Revista de Humanidades: Tecnológico de Monterrey, Monterrey, 24, págs. 83-120.

Beretta Curi, Alcides y Bouret Vespa, Daniela (2004). «La Asociación Rural del Uruguay (1870-1914)». Estudios Interdisciplinarios de América Latina y el Caribe, Tel Aviv, 15 (2). Disponible en: www7.tau.ac.il/ojs/index.php/eial/article/view/895/856.

BuRKE, Peter (1993). «La nueva historia socio-cultural». Historia Social, Valencia, 17, págs. 105-114.

BreZzo, Liliana (2004). «La guerra de la Triple Alianza en los límites de la ortodoxia: mitos y tabúes». Revista Universum, Talca, 19 (1), págs. 10-27.

BURT, Ronald (2005). Brokerage and clousure. An introduction to social capital. Nueva York: Oxford University Press.

Cheroni, Alcion (1966). Tablas cronológicas del Gobierno Departamental de Montevideo (1830-1966). Montevideo: Biblioteca JDM.

СомEт, Catherine (2007). «Capital social et profits des artisans du bâtiment: le poids des incertitudes sociotechniques». Revue Française de Sociologie, París, 1 (48), págs. 67 91.

Delbono FernándeZ, Andrea (2007). «Cambio institucional en el Uruguay moderno e inserción en la economía internacional: transformaciones entre 1870 y 1913». Cuadernos del CLAEH, Montevideo, 30 (1-2), págs. 143-163.

El Banco Comercial a través de un siglo 1857-1957 (1957). Montevideo: Colombino Hnos. S.A.

FERnÁNDEZ SaldañA, José M. (1945). Diccionario uruguayo de biografías (1810-1940). Montevideo: Editorial Amerindia.

Forner Muñoz, Salvador y García Andreu, Mariano (1990). Cuneros y caciques. Alicante: Patronato Municipal del V Centenario de la Ciudad de Alicante.

FREGA, Ana (coord.) (2009). Historia regional e independencia del Uruguay: proceso histórico y revisión crítica de sus relatos. Montevideo: Banda Oriental.

FREGA, Ana (2015). «Proyectos políticos y faccionalismo militar. Ecos de la crisis de la monarquía portuguesa en Montevideo, 1824-1824». Illes i Imperis, Barcelona, núm. 17, págs. 57-90.

GALINDO, José (2017). «Algunas conclusiones sobre el "crony capitalism" y las redes sociales a escala global durante el siglo xx y hasta la actualidad». Istor-Cide: Revista de historia Internacional, Ciudad de México, 2, págs. 7-28.

GiRón, Alicia (1977-1978). «Militarismo y empresas transnacionales en América Latina». Problemas del Desarrollo, Ciudad de México, 8 (32), págs. 122-131.

Hudson, William H. (2018). La tierra Purpúrea. Barcelona: Acantilado.

Imízcoz, José María (2013). «Actores, redes y procesos: reflexiones para una historia más global». Revista da Facultade de Letras, Oporto, Historia, serie III, 5, págs. 115140.

JACOB, Raúl (1996). Más allá de Montevideo: los caminos del dinero. Montevideo: Arpoador. MARICHAL, Carlos (2009). «La crisis mundial de 1873 y su impacto en América Latina». ISTOR, Revista de Historia Internacional (CIDE), Ciudad de México, Ix: 36, págs. 2247. 
Memoria (1860). Memoria de la JEA del Departamento de Montevideo. Montevideo: Imprenta de Dermibio de María.

NúÑEZ GARCíA, Víctor (2010). "Los orígenes del liberalismo mexicano. Elites y grupos de poder en Puebla (1833-1857)». Secuencia. Revista de Historia y Ciencias Sociales, Ciudad de México, 78, septiembre-diciembre, págs. 43-87.

LeVI, Giovanni (1985). La herencia inmaterial. Historia de un exorcista piamontés del siglo XVII. Madrid: Nerea.

PeÑARRUBiA I MARQuÉs, Isabel (1982). «Caciques y cuneros en Mallorca (1869-1905)». Historia 16, Madrid, 71, págs. 27-34.

RAIL, J. y KLACZCO, J. (1981). Uruguay: el país urbano. Montevideo: CLACSO / Ediciones de la Banda Oriental.

Relación (1875). Relación nominal de los declarantes en la Oficina de Contribución Directa en la capital y departamentos con expresión del capital y cuota cobrada por la misma. Montevideo: Imprenta a vapor de El Siglo.

REAL dE AzúA, Carlos (1969). «Ejército y poder en el Uruguay», en El militarismo. Núm. monográfico de Cuadernos de Marcha, Montevideo, 23, marzo.

REYEs AbAdIE, Washington y WiLliman, José Claudio (1969). «La economía del Uruguay en el siglo XIX». Núm. monográfico de Nuestra Tierra, Montevideo, 32.

REVEL, Jacques (1996). «Microanálisis y construcción de lo social». Entrepasados, Buenos Aires, 10, págs. 141-160.

Rodríguez AyçAguer, Ana María (2010). «Eduardo Mac Eachen Alarcón, un descendiente de escoceses en la política uruguaya (1835-1904)». Comunicación en el Seminario Interuniversitario: el sentido del lugar: perspectivas y conexiones uruguayo-escocesas, Montevideo, Facultad de Humanidades Udelar.

RuigómeZ GómEZ, Carmen (1988). «La guerra de la Triple Alianza: un conflicto regional». Quinto Centenario, Madrid, 14, págs. 255-270.

SAGRAdo DoméneCH, José (2015). «Los diputados cuneros a Cortes por Berja (18531864)». Farua: Revista del Centro Virgitano de Estudios Históricos, Berja, 18, págs. 97-108.

SAlterain y HerRera, Eduardo (1975). Latorre. La unidad nacional. Montevideo: Elice.

SANSÓN CORBO, Tomás (2015). «La historiografía uruguaya sobre la guerra de la Triple Alianza. Trayectos, tradiciones, ¿resignificaciones?». Diálogos, 19 (3), págs. 955-979.

SWEDBERG, R. (1997). "Vers une nouvelle sociologie économique: bilan et perspective». Cahiers Internationaux de Sociologie, París, «Sociologies économiques», 103, págs. 237-263.

TALAmANTE PÉREZ, Manuel (2018a). «Relaciones de poder económico y político. El caso de una actividad económica como el tranvía a caballo en el Uruguay de la modernización (1865-1903)». Boletín Americanista, Barcelona, 76, págs. 49-70.

TAlAmANTE PÉREZ, Manuel (2018b). «Poder local y poder nacional: aproximaciones para un estudio de las élites políticas en el Uruguay del militarismo (1876-1886)». En: Lacueva Muñoz, Jaime y Saldaña Fernández, José. Sujetos, espacios y poder. Visiones sobre las élites en América Latina (1810-1910). Valparaíso: Instituto de Historia y Ciencias Sociales, págs. 75-106.

TALAmANTE PÉREZ, Manuel (2019). Las élites socioeconómicas del Uruguay en la época de la modernización y del militarismo: análisis de redes (1876-1903). Tesis de doctorado. Université Toulouse - Jean Jaurès / Universidad de la República del Uruguay. 
TALAmANTE PÉrez, Manuel (2020). «Nuevas aproximaciones para la comprensión del militarismo uruguayo a través de un análisis social». Caravelle. Cahiers du Monde Hispanique et Luso-brésilien, Toulouse, 114, págs. 141-154.

Fecha de recepción: 31 de mayo de 2021

Fecha de aceptación: 15 de septiembre de 2021

Fecha de publicación: 22 de diciembre de 2021 